\title{
Investigation on the Basketball Teaching in Senior High Schools of Zhumadian City
}

\author{
Teng-Fei Yao, Xiao-Fang Liu, Zu-Hua Xie, Zhao-Lian Yuan, Jiang-Hua Li* \\ Key Lab of Training, Monitoring and Intervention of Aquatic Sports of General Administration of Sport of China, Institute of \\ Physical Education, Jiangxi Normal University \\ Nanchang, China
}

\begin{abstract}
To understand the current situation of high school basketball teaching and propose the corresponding countermeasures are important to the sustainable development of basketball in high schools of China. To promote the development of basketball in high schools of China, the basketball teaching in the high schools of Zhumadian City was investigated and analyzed. In this study, students and physical education teachers from Zhumadian High School, Zhumadian First High School and Zhumadian Second High School were investigated to use questionnaires. Based on the current situation of the high school basketball teaching in Zhumadian City, the problems in the high school basketball teaching were found out. These results are helpful to further define the basketball teaching goal, to optimize the teaching content, and to improve the teaching modes.
\end{abstract}

Keywords-Middle school student; Basketball teaching; Current situation; The countermeasures

\section{INTRODUCTION}

The development of basketball in middle schools is the basis of basketball in a region or even a country [1-2]. Its development has a direct impact on whether a basketball at home can sustainably develop [3-4]. At the same time, basketball, as a sports project favored by young students, is also a kind of sport with good exercise value and education, which plays a good role in promoting students' physical and mental development [5]. It is because such basketball has always been regarded as one of the most important parts of physical education in schools [6]. To make basketball play a proper role as an educational method and method depends on the actual effect of basketball teaching [7]. Basketball teaching can make the mental health of students be further improved, so that individuals into the community among them, to promote the overall quality of students [8].

\section{SUBJECTS AND METHODS}

\section{A. Subjects}

Taking Zhumadian High School, No.1 Middle School of Zhumadian City, No.2 High Middle School of Zhumadian City, and $\mathrm{PE}$ teacher of basketball teaching as the investigation object, the article takes the development of high school basketball teaching in Zhumadian City as the research object

\section{B. Methods}

According to the needs of the research, relevant papers and monographs are collected in the Chinese academic journal network, the Bo Shuo dissertations are collected in the China
Excellent Dissertation Database, and the relevant documents are collected in the full foreign language database. And these documents are collated and analyzed, a comprehensive understanding of the research status of the field. The concept of the subject, the feasibility of the subject research, questionnaire design consult experts, professors, scholars, make this study more scientific and rational. Based on the review and interviews of the documents and materials, the author investigated and interviewed the teachers and students of Zhumadian Senior High School based on the topics and subjects of the thesis. According to the basic principles of sociological questionnaire design, "teacher survey questionnaire" and "student questionnaire" were designed, and the opinions of experts were consulted to evaluate the validity of the questionnaire. The survey questionnaire was randomly selected from high school in Zhumadian urban area, and a total of 1432 questionnaires were sent to students and teachers. Among them, 1,318 students 'questionnaires were distributed and 1261 were returned; 114 teachers' questionnaires were distributed and 108 were returned. A total of 1369 questionnaires were collected, with a recovery rate of $95.39 \%$. Among them, 105 were valid questionnaires, 1215 were valid questionnaires, 1320 were valid and $96.42 \%$ were valid. The data will be used Microsoft Excel software and SPSS statistical software for storage, computing and routine processing analysis, which reflects the problems in Zhumadian high school basketball teaching.

\section{RESULTS AND DISCUSSION}

\section{A. Zhumadian senior high school students understand basketball}

Motivation is the purpose of students participating in physical education teaching, and is a "catalyst" for students to actively participate in sports. Good motivation to learn, make students love basketball, basketball more hard practice, better basketball skills and tactics. On the contrary, poor learning motivation will make students have negative emotions, reduce the desire of students to learn, have a negative impact on basketball learning. In short, a good learning motivation can help students learn basketball, poor learning motivation will hinder students' basketball learning.

The motivation of students to learn basketball presents a diversity and diversity. Among them, $47.98 \%$ of the investigated students' learning motivation is to improve their basketball skills. $28.23 \%$ of the investigated students' 
motivation is to exercise and enhance their physical fitness. $11.03 \%$ of the investigated students' motivation to study is $2.14 \%$ and $3.87 \%$ of the surveyed students think that their motivation to learn is to cultivate their social adaptability and work and rest, improve the efficiency of cultural studies, and $6.75 \%$ of the surveyed students choose other. This shows that the vast majority of students participating in basketball motivation is to enhance physical fitness and improve basketball, these motives are good, these good motivation allows students to seriously study in the physical education of basketball skills, and strive to exercise Quality. Of course, there are some students' motivation to study in order to comprehensive evaluation, to cope with the examination. These students are only for the examination qualified, so in the basketball class tends to show negative emotions, do not seriously study skills, basketball teaching and classroom have a certain negative impact.

Students love basketball game determines the basketball teaching is carried out smoothly, is it effective? Only students interested in basketball, in order to be able to pay more attention to this in order to achieve better results in teaching, or even exceed the expected goal of basketball teaching.

TABLE I SCHOOL BASKETBALL ATMOSPHERE SURVEY

\begin{tabular}{|c|c|c|c|c|}
\hline & Very good & Better & General & Not good \\
\hline Frequency (person) & 373 & 487 & 259 & 96 \\
\hline Percentage(\%) & $30.70 \%$ & $40.08 \%$ & $21.32 \%$ & $7.90 \%$ \\
\hline
\end{tabular}

As can be seen from Table 1, $40.08 \%$ and $30.70 \%$ of the surveyed students said that the school basketball atmosphere is good and very good, $21.32 \%$ of the surveyed students said they were not good and only $7.90 \%$ of the total. At present, Zhumadian Senior High School has a good basketball atmosphere, which provides a very favorable environment for the popularization and development of basketball in the campus.

TABLE II STUDENT'S FAVORITE SPORTS STATISTICS SURVEY

\begin{tabular}{|c|c|c|c|}
\hline & Total & Male & Female \\
\hline Basketball & $53.74 \%$ & $30.95 \%$ & $22.80 \%$ \\
\hline Volleyball & $4.61 \%$ & $1.23 \%$ & $3.37 \%$ \\
\hline Football & $10.78 \%$ & $7.16 \%$ & $3.62 \%$ \\
\hline Pingpangball & $10.29 \%$ & $4.44 \%$ & $5.84 \%$ \\
\hline Badminton & $12.26 \%$ & $5.51 \%$ & $6.75 \%$ \\
\hline Aerobics & $2.30 \%$ & $0.16 \%$ & $2.14 \%$ \\
\hline Martial arts & $2.88 \%$ & $2.80 \%$ & $0.08 \%$ \\
\hline Other & $3.13 \%$ & $0.99 \%$ & $2.14 \%$ \\
\hline
\end{tabular}

As shown in Table 2, surveys of students' favorite sports shows that $53.74 \%$ of students surveyed like basketball, $4.61 \%$ like volleyball, $10.78 \%$ like football, Accounted for $10.29 \%$ of ball exercise, $12.26 \%$ liked badminton, aerobics, martial arts and others accounted for $2.30 \%, 2.88 \%$ and $3.13 \%$ respectively. Thus, compared to volleyball, soccer, table tennis and other sports, students prefer basketball, basketball is the high school students favorite sports.

\section{B. The age structure of Zhumadian high school basketball teacher and the proportion of men and women}

Basketball teachers in Zhumadian high school basketball, male teachers accounted for $84.3 \%$, female teachers accounted for $15.7 \%$, engaged in basketball teaching male teachers is far higher than the proportion of female teachers engaged in basketball teaching. Women teachers in basketball teaching in Zhumadian City are relatively scarce and can not meet the needs of male and female physical education teachers for the status of male and female high school students. Physical Education Teachers Article 18 of the Regulations on Physical Education "Schools shall allocate physical education in accordance with the proportions of hours instructed in physical education programs and the need of carrying out extracurricular sports activities in the teacher's general assembly approved by the educational administrations. Teachers: The school should allocate a certain percentage of female physical education teachers according to the number of schoolchildren. "Because female teachers who are engaged in physical education in their daily teaching play a role that is irreplaceable to male physical education teachers for female students in their puberty period, So Zhumadian high school should pay attention to the introduction of high quality female physical education teachers.

Among the PE teachers surveyed, $80 \%$ of the PE teachers are undergraduates, $12 \%$ of the PE teachers have a postgraduate qualification and $8 \%$ of the PE teachers are college level. Due to historical reasons, most of the teachers with tertiary education are Old teachers over 50 years old. Undergraduate and above the proportion of teachers reached $92 \%$, in similar prefecture-level cities, physical education teachers in Zhumadian level is very high, which for the school to carry out basketball and other sports teaching activities provided very favorable conditions.

Among the PE teachers surveyed, $23.81 \%$ hold secondary titles, $48.57 \%$ hold middle school titles, $24.76 \%$ hold senior titles, and another three have special grade teachers of $2.86 \%$. The ratio of secondary education, secondary education and senior education is 1: 2: 1 , with a large proportion of primary teachers.

The survey results show that Zhumadian high school basketball teacher's educational level is generally higher, with a more reasonable age. Most physical education teachers in the title of primary or secondary teacher, senior teacher and junior faculty less. The high school PE teachers in Zhumadian City have strong professional quality and teaching ability, which is of great help and significance for the basketball teaching in Zhumadian High School which can be implemented scientifically and rationally. 


\section{The court and facilities of Zhumadian high school basketball}

TABLE III THE EQUIPMENT CONDITIONS OF ZHUMADIAN CITY HIGH SCHOOL BASKETBALL COURT

\begin{tabular}{|c|c|c|c|}
\hline & Total & $\begin{array}{l}\text { Surveyed } \\
\text { schools }\end{array}$ & Average \\
\hline $\begin{array}{c}\text { Standard } \\
\text { basketball court }\end{array}$ & 120 & 3 & 3.43 \\
\hline Basketball stand & 240 & 3 & 6.86 \\
\hline $\begin{array}{c}\text { Basketball } \\
\text { number }\end{array}$ & 308 & 3 & 88.15 \\
\hline
\end{tabular}

In the surveyed schools (Table 3 ), there were 120 outdoor full basketball courts with an average of 3.43 in each school. There were 240 basketball stands, averaging 6.86 pairs per school. On average, there were 88.15 basketballs available to each school, Outdoor basketball courts, very few schools use plastic venues, most schools use cement or asphalt venue. According to the Ministry of Education issued by the middle school sports equipment and facilities with the notification, for school sports equipment and facilities equipped with a minimum standard. Through investigation, Zhumadian City, the number of schools equipped with basketball at the moment all meet the above minimum standards, school basketball rack equipped with the ability to meet the minimum standards. Basketball is the most popular sport among high school students. However, due to insufficient school space and equipment, the basketball interest of most students has been hit and the basketball activities in schools have also been affected. Therefore, the implementation of the new sports curriculum puts forward higher requirements for venues and equipment. This requires that education authorities and schools should increase their investment in school sports facilities and ensure the smooth running of basketball teaching and student extracurricular activities.

\section{High school basketball teaching content}

Teachers choose to arrange teaching content must be based on the teaching to achieve the goal, the main way to achieve teaching objectives is to choose the teaching content in line with the students' interest and needs, the teaching content directly points to the students can learn knowledge and skills in the teaching process. So the first choice of teaching content is to consider the consistency of teaching objectives, but also pay attention to the scientific content and effectiveness of the teaching content.

Liu Xiaohua of Capital Institute of Physical Education mainly focuses on the teaching content of basketball major [3]. He proposed that basketball teaching materials should standardize teaching contents. The teaching materials include the basic theoretical knowledge of basketball, basic skills and tactics, training arrangements, basketball research methods, Basketball competition rules, rules of referees and many other aspects, but according to the broad teaching content, rigid teaching in accordance with the contents of the textbook has the stability, but the dynamic is not enough, can not reflect the modern basketball connotation of culture, can not reflect the new Curriculum standards advocate the idea of cultivating students' lifelong physical education, but can not achieve the goal of inheritance and development of basketball culture. Therefore, we should closely integrate the theoretical knowledge and rich practical contents of modern basketball science system with the training of modern quality education and innovation ability from the perspective of development so as to enable students to grasp and dominate the complex basketball environment, the law of motion under empty conditions. At the same time, when arranging the teaching contents and dividing the proportions of each part, students should take into account their own knowledge status and skill level. At the same time, the combination of teaching objectives and the development of students' comprehensive qualities and different stages of teaching should be made into continuous, The system as a whole.

\section{E. High school basketball teaching methods}

In the recent period, scholars and experts with the theme of basketball teaching have made innovations in teaching methods and teaching methods in basketball teaching [6]. They try to use the most advanced educational concepts to guide basketball teaching and use the fruits of research and innovation as well as modern teaching equipment in basketball teaching, promoting the basketball teaching reform. In many research results, a variety of effective teaching methods and means are put forward, including diversified teaching methods, induced teaching methods, reverse teaching methods, program teaching methods, contrast teaching methods, appearance teaching methods and group cooperation teaching methods. These teaching methods regard students as the main body of teaching, emphasizing the cooperation and exchange between teachers and students, students and students, the feedback of teaching information and the excitement of students' interest. Among them, Dong Jie and Ji Liu put forward the diversified teaching methods which are the most prominent. In basketball teaching, it refers to various teaching and practice in basketball teaching according to the cognitive process of knowledge, the characteristics of teaching and learning, the individual differences of technical level and the characteristics of class teaching Methods combined into teaching, highlighting the dominant position of student learning, creating a harmonious teaching environment, the establishment of a multi-level twoway communication is conducive to correct behavior of students learning attitude, improve teaching efficiency and enhance learning satisfaction Sense and enhance group cohesion, significantly improve the student basketball scores.

The means of physical education are the medium with information, shape and function that teachers and students use to carry out teaching activities for the purpose of teaching. Physical education teaching methods should be used in accordance with the objectives of teaching, teaching content, the situation of students, school venues and equipment, teaching methods, their own characteristics, teaching hours and efficiency to choose sports teaching methods. 


\section{CONCLUSIONS AND RECOMMENDATIONS}

\section{A. Conclusions}

Most of the schools in Zhumadian high school have a good basketball atmosphere. Students have a strong interest in basketball and a good learning motivation. In addition, the academic qualifications of PE teachers in high schools are generally high, but the age is reasonable. However, the contradiction between homework burden and basketball learning restrains students 'interest in basketball and hinder the improvement of students' basketball. Moreover, since the current teaching arrangements require all PE teachers to teach basketball lessons, many non-basketball PE teachers generally have low skills and tactics and students evaluate the teaching ability of PE teachers in general. School venues and equipment can not meet the needs of existing basketball activities, limiting the development of basketball to some degree.

\section{B. Recommendations}

- Schools should increase capital investment, increase the number of basketball and basketball courts. On the basis of the original increase of basketball court facilities, capital investment, so that facilities under the effective management of play a greater role. Establish and improve site equipment management system to better meet the needs of high school basketball teaching,

- Schools should be based on the actual student, adjust the curriculum and teaching organization, give full play to the expertise of teachers, as far as possible so that basketball professional basketball teacher teaching.

- Appropriate to increase the number of basketball lessons, a reasonable arrangement of the content and difficulty of practice to develop a set of assessment standards for students to improve the level of basketball students.

- $\quad$ Physical education teachers should make great efforts to improve their own basketball level, combine the requirements of new curriculum standard, fully study and develop basketball courses, improve teaching methods and methods, and improve teaching ability. Teachers should take the initiative to take the extracurricular basketball teaching tasks and strive for more students Practice and competition opportunities.

- Adopting various ways to make basketball teachers recognize the importance of modern teaching methods in basketball teaching and pay more attention to training basketball teachers in modern teaching methods such as computer and multimedia. In the classroom, we should realize the students as the main body and realize the change of the role in the teaching process.

\section{ACKNOWLEDGMENT}

This work was supported by the Open Project Program of Key Lab of Training, Monitoring and Intervention of Aquatic Sports of General Administration of Sport of China, Jiangxi Normal University (NO. 201604).

\section{REFERENCES}

[1] F. Wenbin. Comparative Study of Basketball Teaching in China, the United States and China [J]. P. P. \& P., 2010, (25).

[2] J. Liu, Hu Zeng. Physical Education Outlook [M]. East China Normal University Press, 2011, (12)

[3] L. Rui from the comparison of school physical education in foreign countries to see the development trend of our school physical education [J]. Journal of Liaocheng University (Natural Science Edition), 2011, (1)

[4] W. Lei, S. Rong. Discussion on the School-based Development Strategy of Basketball Teaching in Middle Schools [J] .Journal of Sports, 2011, (10).

[5] DZ. Hua. Multimedia technology in basketball teaching application [J]. Shandong Business College of Vocational Technology, 2012, (2).

[6] YJ. Hui.Study on the Current Situation of Basketball Teaching in Junior High Schools of Shuangliao City, Jilin Province [D]: (Master's Thesis), Liaoning Normal University, 2012.

[7] YJ Hui, WT. Wang junior high school basketball teaching status quo and countermeasures [D]. Shandong Normal University master's degree thesis, 2010.

[8] Q. Zhang. Urumqi high school basketball teaching reform and development [J]. Success (Education Edition), 2013, (1). 